\title{
Study of bio-efficacy of entomopahogenic fungi for suppression of termite incidence in maiz
}

\section{B.S. RANA* AND DINESH KACHHAWA}

Department of Entomology, Rajasthan College of Agriculture, Maharana Pratap University of Agriculture and Technology, UDAIPUR (RAJASTHAN) INDIA

\section{ARITCLE INFO}

$\begin{array}{ll}\text { Received } & : 19.06 .2014 \\ \text { Revised } & : 10.08 .2014 \\ \text { Accepted } & : 24.08 .2014\end{array}$

KEY WORDS :

Beauveria bassiana, Metarrhizium anisopliae, Paecilomyces

fumosoroseus, bio-efficacy and termite

*Corresponding author:

\begin{abstract}
Extensive use of chemical insecticides for termite management has lead to hazardous residual impact on plant health. Moreover, they are very expensive and also toxic to human beings. Therefore, there is a demand to develop an alternative safe economic and eco-friendly bio agent to control the termite population under maize field condition. In the present investigation, the bio-agents i.e. Beauveria bassiana, Metarrhizium anisopliae and Paecilomyces fumosoroseus were used @ 5x1013 spore /ha and @ 5x10 ${ }^{13}$ spore/ha FYM to enrich formulation and all the bio-agents have shown the promising results in in vivo in suppression of termite population in maize field. Similarly, the antagonistic fungi improved the germination as well as reduced the plant mortality caused by termite and improved the yield of maize as compared to untreated control. Result of entire study indicated a possibility of obtaining a powerful suppression of termite population by using plant beneficial bio-agents.
\end{abstract}

How to view point the article : Rana, B.S. and Kachhawa, Dinesh (2014). Study of bio-efficacy of entomopahogenic fungi for suppression of termite incidence in maize. Internat. J. Plant Protec., 7(2) : 377381.

HIND AGRICULTURAL RESEARCH AND TRAINING INSTITUTE 